\title{
EFFECT OF A SELF-MANAGEMENT SUPPORT PROGRAM ON DIABETIC FOOT CARE BEHAVIORS
}

\author{
${ }^{1}$ Wipa Sae-Sia, ${ }^{1}$ Khomapak Maneewat and ${ }^{2}$ Titis Kurniawan \\ ${ }^{1}$ Department of Surgical Nursing, Faculty of Nursing, Prince of Songkla University, Thailand \\ ${ }^{2}$ Fundamental of Nursing Department, Faculty of Nursing, Universitas Padjadjaran, \\ Jl. Bandung-Sumedang Km 21 Jatinangor, Sumedang, West Java, Indonesia
}

Received 2012-01-15, Revised 2012-06-13; Accepted 2013-05-04

\begin{abstract}
Diabetic Foot Care Behaviors (DFCB) is the fundamental component of diabetic foot complications prevention. Many diabetic patients, however, did not perform foot care properly. Furthermore, SelfManagement (SM) support program was noted as effective approach improving diabetes patients' behaviors. Unfortunately, there have been no studies published applied this approach to improve DFCB in Indonesia. This study aimed to determine the effectiveness of a self-management support program in improving DFCB in patients with diabetes mellitus in West Java, Indonesia. Quasi-experimental study was conducted with seventy subjects who randomly assigned either to an experimental $(n=35)$ or a control group $(n=35)$. The subjects in the experimental group received a five-week diabetic foot care SM support program. The subjects in the control group received standard care. Their DFCB was evaluated in the fifth week of intervention using a DFCB Questionnaire. The results showed that the DFCB in the experimental group was significantly higher $(\mathrm{M}=67.43, \mathrm{SD}=5.83)$ than that in the control group $(M=52.60, S D=8.6)(p<0.001)$. The result indicates that a five-week $S M$ program effectively enhanced DFCB. Thus, nurses are recommended to apply this program in improving DFCB in order to prevent diabetic foot ulcers or other foot complications.
\end{abstract}

Keywords: Diabetes Mellitus, Diabetic Foot Care Behaviors, Self-Management

\section{INTRODUCTION}

The prevalence of Diabetes Mellitus (DM) and its complications are constantly increasing in many parts of the world, including in Indonesia, where the number of cases among adults (20-79 years) is predicted to increase from 7 million in 2000-12 million in 2030. Additionally, $\mathrm{DM}$ is now the eighth most common cause of death in Indonesia (MOHRI, 2007).

One of the most disabling complications of DM is Diabetic Foot Ulcers (DFU) which affect $15-25 \%$ of diabetic patients and may lead to gangrene, infection and/or foot amputation (Singh et al., 2005). These complications can lead to severe adverse effects including a high financial burden, physical disability, depression, low quality of life and high mortality (Abdelgadir et al., 2008; Stockl et al., 2004). Since effective long term treatment of DFU is difficult, costly and time consuming and since ulcers often reoccur even after healing (Ghanassia et al., 2008; Ragnarson-Tennvall and Apelqvist, 2004), their prevention is very important. DFU prevention is of even greater importance in developing countries where health service resources, diagnoses, treatments and innovations are limited (WDF, 2010).

Proper daily foot care is an essential, low cost and effective part of DFU prevention. Performing daily foot care routines enables diabetic patients to detect foot abnormalities and injuries earlier and as a result to reduce or even prevent the risk of foot ulceration effectively (Calle-Pascual et al., 2001; Hokkam, 2009). However, many diabetic patients do not perform daily foot care appropriately, for instance, failing to conduct a daily foot self-inspection, walking barefoot or wearing improper footwear, improperly trimming their Corresponding Author: Wipa Sae-Sia, Department of Surgical Nursing, Faculty of Nursing, Prince of Songkla University, Thailand 
toenails, or using unsafe water for washing their feet (Gulliford and Mahabir, 2002; Khamseh et al., 2007).

Patients living with chronic diseases, such as DM, have to learn to self-monitor, to make appropriate decisions, to improve relevant skills and to change aspects of their lifestyle on a day-to-day basis in order to control and manage their symptoms and complications (Bourbeau, 2008). A Self-Management (SM) support program is one of the most effective strategies in improving health-related behaviors in chronically ill patients (Bodenheimer and Handley, 2009; Bodenheimer et al., 2002; DeWalt et al., 2009; Fan and Sidani, 2009; Handley et al., 2006). SM support programs include collaboration between patients and health care providers to ensure that patients actively adopt specific behaviors to prevent the adverse effects of chronic diseases (Bourbeau, 2008). However, to our knowledge, there have been no studies published of SM support programs applied to improve Diabetic Foot Care Behavior (DFCB) in patients suffering from $\mathrm{DM}$ in Indonesia. The current day-to-day practices relating to the care of patients with DM are mainly focused on diet, exercise and medication. However, general information on diabetic foot care is rarely provided by physicians unless patients show symptoms of diabetic neuropathy, or nurses/physicians find evidence of foot abnormalities. Further, it was found that using only educational programs limited the extent to which diabetic patients engaged in behavioral change and recommended integrating self-management with educational programs as a mean of successfully increasing patients' participation in managing their own chronic illness (Bodenheimer et al., 2002; Ellis et al., 2004). It is, therefore, essential to develop SM support programs to encourage Indonesian diabetic patients to improve their DFCB.

This study set out to test the effectiveness of an SM support program in improving DFCB in Indonesian diabetic patients. The research hypothesis was that DFCB in the experimental group would be better than that in the control group.

\section{MATERIALS AND METHODS}

\subsection{Conceptual Framework}

The SM support program was developed based on the self-management method proposed by Kanfer and Goldstein (1991) and the diabetic foot care standards promoted by the Indian Health Diabetes Best Practice Foot Care (IHSDDTP, 2009) program and the Registered Nurses' Association of Ontario (RNAO, 2005). The SM support program was modified to be a five-week intervention aimed at encouraging diabetic patients to achieve the desired DFCB effectively. The five-week SM program consisted of a sequence of three stages: Self-monitoring, self-evaluation and self-reinforcement.

The self-monitoring stage involved the patients themselves reflecting on their current DFCB. The selfevaluation stage included giving individual foot care education sessions, conducting discussions to evaluate the subjects' current DFCB and identifying DFCB component(s) that needed to be improved. The selfreinforcement stage consisted of giving feedback regarding the patients' current DFCB, assisting the patients to develop their own self-reinforcement, assisting the patients in making decisions about the maintenance, modification, or improvement of their current DFCB and assisting each patient to set a goal and an action plan according to the decisions made. Thereafter, potential barriers and the patient's selfconfidence level about implementing the action plan were evaluated and the patient was given a brief counseling session in regard to setting alternative goals or revising their action plan. These activities were integrated and repeated in follow-up sessions during the second to the fifth week of the program.

\subsection{Method}

\subsubsection{Setting and Subjects}

The sample size was calculated using power analysis with a power of 0.80 , a significance level of 0.05 and an effect size of 0.6. This effect size was based on the average effect size of several strategies applied in previous studies using SM support programs (Fan and Sidani, 2009).

The subjects in the study consisted of patients with DM who were recruited from a diabetic unit of a district general hospital in West Java, Indonesia. The subjects included in the study were aged between 18 and 65 years old, were able to read and speak the Indonesian language and had no severe vision or hearing problems or other disabilities and were able to be contacted by telephone. Subjects were excluded from the study if they developed severe complications including severe diabetic retinopathy and joint problems, or were hospitalized during the study period or otherwise became unable to perform foot care independently. The subjects were randomly assigned to either the control $(n=35)$ or the experimental $(n=35)$ group using matched criteria of foot ulcer history and foot problems.

\subsection{Instruments}

The instruments used in this study were of two types: those used during the intervention and those used to measure the outcome of the study. The instruments used 
in the intervention included a prior foot care knowledge questionnaire, a teaching guideline, a diabetic foot care booklet, a self-confidence scale and a level of goal achievement scale, all of which were used during the SM support program. The instrument used to measure the outcome of the study was a DFCB Questionnaire.

The prior diabetic foot care knowledge questionnaire was developed by the researchers based on a review of relevant literature. It was used to assess the subject's prior knowledge about DFCB and the information collected was used to help guide the principal investigator in providing appropriate information about DFCB during the education sessions. The content validity of this instrument was established based on the approval of three experts. The KR 20 reliability coefficient was 0.63 .

The teaching guideline and diabetic foot care booklet was developed based on the foot care standards promoted by the Indian Health Diabetes Best Practice Foot Care (IHSDDTP, 2009) program and the RNAO (2005). The contents were focused on DFCB. The DFCB information was given to the subjects by the principal investigator through a brief verbal explanation, in subsequent discussions and via a booklet and a video.

The self-confidence scale was used to estimate the subjects' level of confidence that they could successfully perform the action plans which were developed. It was based on a 0-10 numeric rating scale in which 0 indicated that the subject had no confidence at all and 10 indicated that they had total confidence. The subjects were given support and encouragement to help them to maintain a high level of confidence of at least 7 to ensure that the goal(s) set were achievable (Bodenheimer et al., 2007). If the subjects had a selfconfidence level of less than 7 , they were encouraged to modify the goal they were aiming to achieve to one which was more realistically achievable.

The level of goal achievement was measured and recorded weekly by the principal investigator. The goal achievement level each week was used as the basis for discussing with the subjects whether they had achieved the goal set or not. The subjects gained positive or negative self-reinforcement according to whether or not they had successfully achieved their goal.

The diabetic foot care behaviors (pre and post-test) Questionnaire was used to measure the DFCB of the subjects. This questionnaire was a modified version of the Nottingham Assessment of Functional Foot-care Questionnaire (NAFF) (Lincoln et al., 2007). The modified version of the questionnaire was translated into an Indonesian version using the back translation method. The content validity was established based on the approval of three experts. The Cronbach's alpha reliability coefficient of the modified version of the NAFF in the Indonesian language was established based on a trial conducted on 20 patients with DM and was found to be 0.72 .

\subsection{Ethicss}

Before initiating the study, ethical approval and permission for the collection of data were obtained from the Faculty of Nursing, Prince of Songkla University, Thailand and from the district general hospital in West Java, Indonesia where the study was conducted. Informed consent was also obtained from the subjects prior to the commencement of data collection from them.

\subsection{Study Procedure}

A five-week SM support program was developed based on the three stages of the self-management method outlined by Kanfer and Goldstein (1991) as mentioned above in the Conceptual Framework section. The principal investigator was the only person who implemented the study program. At the commencement of the study, the subjects' demographic characteristics, their prior foot care knowledge and their level of selfconfidence in performing DFCB were assessed as well as their perception of diabetic foot care behavior. The Subjects were given an individual education session and a booklet outlining suitable DFCB in the first week of the program. The subjects were also encouraged to set weekly action plans and the goals they sought to attain during their participation in this study. During the second through the fourth weeks, the subjects were contacted weekly by a phone-call follow-up in order to assess their progress in improving their DFCB and to briefly counsel them in respect of any actions that they had found difficult to complete. The subjects were asked to attempt self-reinforcement in respect of improvements achieved during that week. At the end of the phone call, the subjects were encouraged to develop DFCB improvement goals and action plans for the forthcoming week. In the fifth week, the subjects were given a brief counseling on the day of their regular hospital check-up at the diabetic unit, to follow up their progress and the improvement in their DFCB was assessed using the DFCB (post-test) questionnaire.

\subsection{Data Analysis}

Descriptive statistics were used describe the demographic, clinical characteristics of the subjects and their DFCB. The frequency-data were analyzed using chi square and Fisher exact tests in which independent t-tests was used to test for significant differences between the experimental and control groups in particular for significant differences in their 
DFCB. A repeated measures Analysis of Variance (ANOVA) was employed to compare the subjects' levels of confidence during the study.

\section{RESULTS}

\subsection{Demographic Data and Clinical Information}

A comparison of the experimental and control subjects' demographic data, their prior knowledge of foot care and their clinical characteristics found only significant differences in the data relating to their latest blood glucose levels and co-morbid diseases. The latest blood glucose level in the experimental group was higher than that in the control group $(\mathrm{t}=-2.03, \mathrm{p}=0.046)$ and the number of subjects without co-morbid diseases in the experimental group was significantly higher than that in the control group $\left(\chi^{2}=4.69, \mathrm{p}=0.03\right)$.

Most of the subjects in both the experimental and the control groups were not new DM cases and more than two-thirds of them had foot problems (71.43\%). Although almost all of them attended the clinic for regular checkups $(94.29 \%)$, most of them $(80 \%)$ had never received diabetic foot care information (Table 1 and 2).

\subsection{Self-Confidence Level}

The subjects' self-confidence level was monitored only in the experimental group. The highest mean level of self confidence (8.69) was found in the first week, as compared to the second (8.17), third (8.29) and fourth (8.29) weeks. A repeated measures Analysis of Variance (ANOVA) found that there was a significant difference in the self-confidence levels across the four weeks of the intervention $(\mathrm{F}=3.35, \mathrm{p}=0.02)$. However, pair-wise comparisons (Bonferroni) only showed there to be a significant difference in the mean levels of selfconfidence between the first and the second weeks of the intervention $(\mathrm{p}=0.04)$.

Table 1. Frequencies and percentages of demographic data and clinical information of in relating to the experimental and control

\begin{tabular}{|c|c|c|c|c|}
\hline Characteristics & $\begin{array}{l}\text { Experimental Group } \\
(\mathrm{n}=35) \\
\mathrm{n}(\%)\end{array}$ & $\begin{array}{l}\text { Control Group } \\
(\mathrm{n}=35) \\
\mathrm{n}(\%)\end{array}$ & $\chi^{2}$ & $\mathrm{p}$ \\
\hline Gender & & & $0.24^{\mathrm{a}}$ & 0.63 \\
\hline Male & $15(42.86)$ & $13(37.14)$ & & \\
\hline Female & $20(57.14)$ & $22(62.86)$ & & \\
\hline Marital Status & & & $0.97^{\mathrm{a}}$ & 0.32 \\
\hline Married & $28(80.00)$ & $31(88.57)$ & & \\
\hline Widowed & $7(20.00)$ & $4(11.43)$ & & \\
\hline Religion (Islam) & $35(100.00)$ & $35(100.00)$ & 0.00 & 1.00 \\
\hline Level of Education & & & $0.36^{\mathrm{a}}$ & 0.83 \\
\hline Basic education & $6(17.14)$ & $8(22.86)$ & & \\
\hline Senior high school & $11(31.43)$ & $10(28.57)$ & & \\
\hline University & $18(51.43)$ & $17(48.57)$ & & \\
\hline Occupation & & & $0.35^{\mathrm{b}}$ & 0.50 \\
\hline Healthcare related & $1(2.86)$ & $2(5.71)$ & & \\
\hline Non-healthcare related & $34(97.14)$ & $33(94.29)$ & & \\
\hline Check up & & & $0.00^{\mathrm{b}}$ & 1.00 \\
\hline Regularly & $33(94.29)$ & $33(94.29)$ & & \\
\hline Irregularly & $2(5.71)$ & $2(5.71)$ & & \\
\hline DM foot care information & & & $0.00^{\mathrm{a}}$ & 1.00 \\
\hline Never got information & $28(80.00)$ & $28(80.00)$ & & \\
\hline Had got the information & $7(20.00)$ & $7(20.00)$ & & \\
\hline Foot conditions & & & $0.00^{\mathrm{a}}$ & 1.00 \\
\hline No complaints of foot problems & $10(28.57)$ & $10(28.57)$ & & \\
\hline $\begin{array}{l}\text { Had complaints of neuropathy } \\
\text { symptoms and/or other foot problems }\end{array}$ & $25(71.43)$ & $25(71.43)$ & & \\
\hline Co-morbid diseases & & & $4.69^{\mathrm{a}}$ & 0.03 \\
\hline No co-morbid disease & $20(57.14)$ & $11(31.43)$ & & \\
\hline At least one co-morbid disease & $15(42.86)$ & $24(68.57)$ & & \\
\hline
\end{tabular}

Note: ${ }^{a}=$ Chi square test, ${ }^{b}=$ Fisher exact test 
Table 2. Means, Standard Deviations (SD), Medians, Minimum (Min) and Maximum (Max) of Ages, Latest Blood Glucose Level, Diabetes Mellitus Duration, Income and Prior Knowledge of DFCB of the Experimental and Control Groups $(\mathrm{N}=70)$

\begin{tabular}{|c|c|c|c|c|c|c|}
\hline \multicolumn{2}{|l|}{ Variable } & \multicolumn{2}{|l|}{$\begin{array}{l}\text { Experimental group } \\
(\mathrm{n}=35)\end{array}$} & $\begin{array}{l}\text { Control group } \\
(\mathrm{n}=35)\end{array}$ & $\mathrm{t}$ & $\mathrm{p}$ \\
\hline & & $\mathrm{M}(\mathrm{SD})$ & & $\mathrm{M}(\mathrm{SD})$ & & \\
\hline Age (years) & & $53.54(7.34)$ & & $52.20(6.13)$ & $-0.83^{c}$ & 0.410 \\
\hline Latest BG (mg\%) & & $179.60(67.57)$ & & $150.69(50.39)$ & -2.03 & 0.046 \\
\hline Income (US\$) & & $265.53(92.40)$ & & $290.18(105.38)$ & 0.86 & 0.390 \\
\hline Prior knowledge of D & & $7.00(1.00)$ & & $7.03(1.56)$ & 0.09 & 0.930 \\
\hline & Median & Min-Max & Median & Min-Max & $\mathrm{Z}$ & $\mathrm{p}$ \\
\hline DM duration (years) & 4.00 & $1-23$ & 3.00 & $0.1-18$ & -1.96 & 0.050 \\
\hline
\end{tabular}

Note: $\mathrm{BG}=$ Blood glucose,${ }^{\mathrm{c}}=$ equal variance not assumed $(\mathrm{df}=65.91)$

Table 3. Means and Standard Deviations (SD) of Diabetic Foot Care Behaviors Pre-Test and Post-Test Score in the Experimental and the Control Group ( $=70)$

\begin{tabular}{lllll}
\hline \multirow{5}{*}{ Variable } & $\begin{array}{l}\text { Experimental } \\
\text { Group } \\
(\mathrm{n}=35)\end{array}$ & $\begin{array}{l}\text { Control } \\
\text { Group } \\
(\mathrm{n}=35)\end{array}$ & & \\
& $\mathrm{M}(\mathrm{SD})$ & $\mathrm{M}(\mathrm{SD})$ & $\mathrm{t}$ & $\mathrm{p}$ \\
\hline Pre- test DFCB & $51.09(9.12)$ & $51.43(8.99)$ & 0.16 & 0.88 \\
Post- test DFCB & $67.43(5.83)$ & $52.60(8.60)$ & $-8.45^{\mathrm{c}}$ & 0.00
\end{tabular}

Note: ${ }^{\mathrm{c}}=$ equal variance was not assumed $(\mathrm{df}=59.80)$

\subsection{Level of Goal Achievement}

Almost all the subjects $(n=33,94.36 \%)$ completely achieved their weekly goals in the first week. However, the percentage of subjects who completely achieved their goals was found to have decreased to figures ranging from $60-70 \%$ during the follow-up interviews in the second, third and the fourth weeks.

\subsection{Diabetic Foot Care Behaviors}

The mean pre-test DFCB score $(\mathrm{M}=51.09, \mathrm{SD}=$ 9.12) of the experimental group was not found to be significantly different from that of the control group (M $=51.43$, SD = 8.99). However, the DFCB (post-test score) after the implementation of the SM support program in the experimental group $(\mathrm{M}=67.43, \mathrm{SD}=$ 5.83) was significantly higher than that in the control group $(\mathrm{M}=52.60, \mathrm{SD}=8.60)(\mathrm{p}=0.00)($ Table 3) .

\section{DISCUSSION}

It was evident that the five-week diabetic foot care SM support program was effective in improving the DFCB of the experimental group of patients with DM from West Java, Indonesia. These findings are consistent with previous studies where SM support programs have been effective in improving patients' DFCB (Corbett, 2003; Deakin et al., 2006; Lincoln et al., 2008;
McMurray et al., 2002; Vatankhah et al., 2009). All these previous studies reported an improvement in DFCB when the subjects participated in studies lasting 6 and 12 weeks (Corbett, 2003), 6 months (Vatankhah et al., 2009), 12 months (Lincoln et al., 2008; McMurray et al., 2002) and 14 months (Deakin et al., 2006). However, the present study noted improved DFCB after only a four week intervention period.

In this study, the SM support program incorporated different foot care strategies as well as monitoring and enhancing of the level of the subjects' self-confidence and played an important role in encouraging the diabetic patients to improve their DFCB in a number ways. First, the use of self-reflection as a strategy encouraged the subjects to consciously monitor their DFCB and increased their awareness of their actual behaviors. Next, in the self-evaluation stage, the subjects were assisted and encouraged to assess whether their current DFCB met the desired DFCB criteria or not and to identify the DFCB components which needed to be improved. Additionally, through self-reinforcement activities, the subjects were encouraged to decide whether they wanted to maintain, modify, or improve their DFCB and thus understand what activities they needed to undertake to improve their DFCB. Furthermore, the SM program placed value on the subjects as experts with knowledge of what is best for their own lives. As a result, they were able to make their own decisions about the selection of their goals and the action plans to achieve them. In common with previous studies, it was found that when the subjects were actively involved in the SM support program, there was a high probability that they would successfully improve their behaviors (Bodenheimer et al., 2002; Handley et al., 2006).

The combined educational strategies applied in this study also supported improvements in DFCB. The individual education sessions allowed the subjects to gain knowledge and also allowed them to intensively discuss any particular additional information they 
needed. In addition, the booklet given to the subjects guided them in performing their daily DFCB. Previous study similarly reported that individual education sessions combined with an explanatory booklet were effective in improving the patients' diabetic foot care knowledge and behaviors within a period of 6 months (Vatankhah et al., 2009). Furthermore, the use of counseling related action plans and discussion of the subjects' difficulties in performing DFCB was instrumental in strengthening their problem solving skills, allowing them to overcome barriers in achieving the behaviors they wanted to implement (DeWalt et al., 2009).

The partnership between the subjects and the principal investigator also provided a positive environment for DFCB improvement. In this study, the principal investigator acted as a facilitator who regularly evaluated and provided feedback on the subjects', actual DFCB and encouraged them to improve their DFCB and to reflect on the improvement or progress in their behaviors. This relationship assisted the subjects and the principal investigator to build effective communication and trust which was effective in improving the subjects' perseverance in performing the required actions, as has been noted in other studies (Fox et al., 2009; Martin et al., 2005; O'Malley et al., 2004). In addition, the feedback and encouragement provided was also effective in facilitating improvements in the subjects' behaviors (Bodenheimer et al., 2007; Bodenheimer and Handley, 2009). The cultural background of the Indonesian subjects also enhanced the successful building of trust in the relationship between the principal investigator and the subjects. In Asian cultures, patients give high respect to healthcare providers. This underlying attitude has the potential to improve the subjects' motivation to perform the required actions and to improve their DFCB.

Another strategy that contributed to the positive outcome of this study was the setting of individual goals and action plans to achieve those goals. The session at which DFCB improvement goals were set and action plans were formulated encouraged each subject to consciously engage in the process of changing their behaviors by adopting their own goals and action plans as previously noted by Bodenheimer and Handley (2009). These goals and action plans also provided clear guidance for the subjects as to what activities needed to be undertaken and how the desired goals were to be achieved. Additionally, the manner in which the goals were set allowed the subjects to set the most achievable goal first and once that goal was achieved that served to strengthen the subject's self-confidence, which in turn provided encouragement for them to successfully achieve further goals (Bodenheimer and Handley, 2009; DeWalt et al., 2009).

Additionally, the evaluation of the subjects' selfconfidence allowed them to set appropriate goals and action plans based on their level of self-confidence, which resulted in a greater probability of the subjects achieving their goals (Bodenheimer et al., 2002; Corbett, 2003). Detailed explanations of the goals, action plans and the goal achievement levels recorded in the current study have already been published in a separate article (Kurniawan et al., 2011).

DeWalt et al. (2009) reported that the use of a goal setting and action planning strategy combined with education sessions and brief counseling were effective in improving the patients' self-confidence to manage their diabetes foot care behavior. The use of the goal setting and action planning strategy was also reported to be effective in encouraging patients to adopt healthier behaviors (Bodenheimer and Handley, 2009; Handley et al., 2006; DeWalt et al., 2009; Cullen et al., 2001). Unfortunately, the findings of the present study were not able to determine whether the intervention given improved the subjects' level of self-confidence and whether that further encouraged the subjects to improve their behaviors as was reported in the study conducted by DeWalt et al. (2009). In the present study, the researcher only evaluated the subjects' levels of self-confidence after they had undertaken the diabetic foot care SM support program. In addition, the subjects' selfconfidence scores were adjusted during the selfconfidence evaluation. For subjects who reported selfconfidence levels of less than 7, the goals and action plans were adjusted downwards until the subjects' selfconfidence scale increased to at least 7 out of 10.7 .

The weekly follow-up and counseling also provided regular encouragement, facilitated the continuous improvement of DM knowledge and encouraged the subjects to exercise responsibility, skills and motivation towards achieving their goals. Bodenheimer and Handley (2009) also noted that the combination of the setting of behavioral change goals and follow-up intervention resulted in more behavioral changes than did the setting of goals alone without follow-up intervention.

\section{CONCLUSION}

The five-week diabetic foot care self-management support program employed in this study was effective in facilitate encouraging Indonesian diabetic patients to 
improve their DFCB. However, the degree to which the findings of this study can be generalized might be limited, since the subjects were recruited from only one setting with all of them being less than 65 years old and all of them being Muslims. In addition, a DFCB Questionnaire that measures only the subjects' selfreporting of their foot care activities may not accurately reflect their actual foot care behaviors.

However, the results lead us to strongly recommend nurses and/or other healthcare providers to utilize this program, particularly those working in an outpatient setting in Indonesian contexts. In addition, the authors recommend the replication of the design of this study in multiple settings with larger samples, including older subjects and using longer durations of intervention and using observations of actual DFCB as the data collection method in order to further clarify the efficacy of SM programs, to strengthen the evidence in their favor and to maximize the benefits for DM patients across Indonesian and on a global basis.

\section{ACKNOWLEDGEMENT}

The researchers are deeply grateful to all the subjects who participated in this study for their valuable time and the precious information they shared, the director of Sumedang district general hospital for permission to conduct this study, the reviewers who evaluated the validity of the instruments used in this study, the co-authors for their support and valuable suggestions and to all other contributors.

\section{REFERENCES}

Abdelgadir, M., W. Shebeika, M. Eltom, C. Berne and K. Wikblad, 2008. Health related Quality of life and sense of coherence in Sudanese diabetic subjects with lower limb amputation. Tohoku J. Exp. Med., 217: 45-50. DOI: 10.1620/tjem.217.45

Bodenheimer, T. and M.A. Handley, 2009. Goal-setting for behavior change in primary care: An exploration and status report. Patient Educ. Counse, 76: 174180. DOI: 10.1016/j.pec.2009.06.001

Bodenheimer, T., C. Davis and H. Holman, 2007. Helping patients adopt healthier behaviors. Clin. Diabet., 25: 66-70. DOI: 10.2337/diaclin.25.2.66

Bodenheimer, T., K. Lorig, H. Holman and K. Grumbach, 2002. Patient self-management of chronic disease in primary care. J. Am. Med. Assoc., 19: 2469-2475. DOI: 10.1001/jama.288.19.2469
Bourbeau, J., 2008. Clinical decision processes and patient engagement in self-management. Dis. Manage. Health Outcomes, 16: 327-333. DOI: 10.2165/0115677-200816050-00009

Calle-Pascual, A.L., A. Duran, A. Beneda, M.I. Calvo and A. Charro et al., 2001. Reduction in Foot Ulcer Incidence Relation to compliance with a prophylactic foot care program. Diabet. Care, 24: 405-407. DOI: 10.2337/diacare.24.2.405

Corbett, C.F., 2003. A randomized pilot study of improving foot care in home health patients with diabetes. Diabet. Educ., 29: 273-282. DOI: 10.1177/014572170302900218

Cullen, K.W., T. Baranowski and S.P. Smith, 2001. Using goal setting as a strategy for dietary behavior change. J. Am. Dietetic Assoc., 101: 562-566. DOI: 10.1016/S0002-8223(01)00140-7

Deakin, T.A., J.E. Cade, R. Williams and D.C. Greenwood, 2006. Structured patient education: The Diabetes X-PERT Programme makes a difference. Diabet. Med., 23: 944-954. DOI: 10.1111/j.14645491.2006.01906.x

DeWalt, D.A., T.C. Davis, A.S. Wallace, H.K. Seligman and B. Bryant-Shilliday et al., 2009. Goal setting in diabetes self-management: Taking the baby steps to success. Patient Educ. Counsel., 77: 218-223. DOI: 10.1016/j.pec.2009.03.012

Ellis, S.E., T. Speroff, R.S. Dittus, A. Brown and J.W. Pichert et al., 2004. Diabetes patient education: A meta-analysis and meta-regression. Patient Educ. Counsel., 52: 97-105. DOI: 10.1016/S07383991(03)00016-8

Fan, L. and S. Sidani, 2009. Effectiveness of diabetes self-management education intervention elements: A meta-analysis. Canad. J. Diabet., 33: 18-26. DOI: 10.1016/S1499-2671(09)31005-9

Fox, S.A., J. Heritage, S.E. Stockdale, S.M. Asch and N. Duan et al., 2009. Cancer screening adherence: Does physician-patient communication matter? Patient Educ. Counsel., 75: 178-184. DOI: 10.1016/j.pec.2008.09.010

Ghanassia, E., L. Villon, J.F.T.D. Dieudonne, C. Boegner and A. Avignon et al., 2008. Long-term outcome and disability of diabetic patients hospitalized for diabetic foot ulcers. Diabet. Care, 31: 1288-1292. DOI: $10.2337 / \mathrm{dc} 07-2145$

Gulliford, M.C. and D. Mahabir, 2002. Diabetic foot disease and foot care in a Caribbean community. Diabet. Res. Clin. Pract., 56: 35-40. DOI: 10.1016/S0168-8227(01)00343-6 
Handley, M., K. MacGregor, D. Schillinger, C. Sharifi and S. Wong et al., 2006. Using action plans to help primary care patients adopt healthy behaviors: A descriptive study. J. Am. Board Family Med., 19: 224-231. DOI: 10.3122/jabfm.19.3.224

Hokkam, E.N., 2009. Assessment of risk factors in diabetic foot ulceration and their impact on the outcome of the disease. Primary Care Diabet., 3: 219-224. DOI: 10.1016/j.pcd.2009.08.009

IHSDDTP, 2009. Indian health diabetes best practice foot care. Indian Health Service Division of Diabetes Treatment and Prevention.

Kanfer, F.H. and A.P. Goldstein, 1991. Helping People Change: A Textbook of Methods. 4th Edn., Pergamon Press, New York, ISBN-10: 0080378935, pp: 488.

Khamseh, M.E., N. Vatankhah and H.R. Baradaran, 2007. Knowledge and practice of foot care in Iranian people with type 2 diabetes. Int. Wound J., 4: 298302. DOI: 10.1111/j.1742-481X.2007.00381.x

Kurniawan, T., W. Sae-Sia, K. Maneewat and W. Petpichetchian, 2011 The effect of a selfmanagement support program on the achievement of goals in diabetic foot care behaviors in indonesian diabetic patients. Nurse Media J. Nurs., 1: 195-210.

Lincoln, N.B., K.A. Radford, F.L. Game and W.J. Jeffcoate, 2008. Education for secondary prevention of foot ulcers in people with diabetes: A randomised controlled trial. Diabetologia, 51: 1954-1961. DOI: 10.1007/s00125-008-1110-0

Lincoln, N.B., W.J. Jeffcoate, P. Ince, M. Smith and K.A. Radford, 2007. Validation of a new measure of protective footcare behaviour: The Nottingham Assessment of Functional Footcare (NAFF). Pract. Diabet. Int., 4: 207-211. DOI: 10.1002/pdi.1099

Martin, L.R., S.L. Williams, K.B. Haskard and M.R. DiMatteo, 2005. The challenge of patient adherence. Ther. Clin. Risk Manage., 1: 189-199. PMID: 18360559
McMurray, S.D., G. Johnson, S. Davis and K. McDougall, 2002. Diabetes education and care management significantly improve patient outcomes in the dialysis unit. Am. J. Kidney Dis., 40: 566-575. PMID: 12200809

MOHRI, 2007. Indonesian country profile 2006. Center for Data and Information, Ministry of Health Republic of Indonesia. Jakarta.

O'Malley, A.S., V.B. Sheppard, M. Schwartz and J. Mandelblatt, 2004. The role of trust in use of preventive services among low-income AfricanAmerican women. Preventive Med., 38: 777-785. DOI: 10.1016/j.ypmed.2004.01.018

Ragnarson-Tennvall, G. and J. Apelqvist, 2004. Healtheconomic consequences of diabetic foot lesions. Clin. Infec. Dis., 39: 132-139. DOI: 10.1086/383275

RNAO, 2005. Assessment and Management of Foot Ulcers for People with Diabetes. Registered Nurses' Association of Ontario, Canada.

Singh, N., D.G. Armstrong and B.A. Lipsky, 2005. Preventing foot ulcers in patients with diabetes. J. Am. Med. Assoc., 293: 217-228. DOI: 10.1001/jama.293.2.217

Stockl, K., A. Vanderplas, E. Tafesse and E. Chang, 2004. Costs of lower-extremity ulcers among patients with diabetes. Diabet. Care, 27: 2129-2134. DOI: $10.2337 /$ diacare.27.9.2129

Vatankhah, N., M.E. Khamseh, Y.J. Noudeh, R. Aghili and H.R. Baradaran et al., 2009. The effectiveness of foot care education on people with type 2 diabetes in Tehran, Iran. Primary Care Diabet., 3: 73-77. DOI: $10.1016 /$ j.pcd.2009.05.003

WDF, 2010. Diabetes fact. World Diabetes Foundation. 